\title{
On the Pragmatic Patterns of Chinese College English Learners' Compliment Responses
}

\author{
Ge Bai ${ }^{1}$ \\ ${ }^{1}$ School of Arts, Northwest University, Xi'an, Shaanxi Province, P. R. China \\ Correspondence: Ge Bai, 1 Xuefu Ave., Guodu Education and Hi-tech Industries Zone, Chang'an District, Xi'an, \\ 710127, Shaanxi Province, P.R. China. Tel: 86-187-2909-5550. E-mail: baikou@snnu.edu.cn
}

Received: May 23, 2015 Accepted: July 10, 2015 Online Published: July 30, 2015

doi:10.5539/ijel.v5n4p106 URL: http://dx.doi.org/10.5539/ijel.v5n4p106

\begin{abstract}
The purpose of this research is to investigate the pragmatic features of Chinese college EFL learners' compliment responses (CR) in English. Since nowadays there is a large population learning English in China and there are limited researches on how the English language is used by Chinese EFL learners, to study the patterns of Chinese EFL learners' use of English is significant.

The data of this study were collected by role play. Twelve short films which contain compliments from native English speakers were designed and recorded. These scenes were controlled by four variables: gender, social status, types of compliments and the formality of the situation. Then these short films were played to 360 Chinese undergraduate students which were divided into 12 groups. The compliment responses of these participants were recorded immediately. Then, these records were transcribed and the data was analyzed statistically with the reference of the four variables.

The results of the analysis indicate that a majority of Chinese EFL learners tend to accept the compliment while seldom Chinese EFL learners still apply non agreement as their CR strategy. Also, Chinese EFL learners prefer to apply a mixed CR strategy when they are complimented and they prefer to accommodate a combined pragmatics which is based on Chinese and English pragmatics. Chinese EFL learners could respond to compliments in English in several CR strategies that did not discussed in previous studies. The four variables of gender, social status, types of compliments and the formality of the situation have a huge influence on Chinese English learners' responses to compliments in English.
\end{abstract}

Keywords: compliment, compliment responses, politeness principle, Chinese EFL

\section{Introduction}

Since the 'First Contact' between English speakers and Chinese people in 1637 in the coastal area of southern China (Bolton, 2002, p. 181), the English language has spread in China intermittently for almost four hundred years. Nowadays, there is a large population learning English in China and the influence of English in Chinese society is increasing, a variety of English with Chinese features is forming. Since there are limited researches on how English language is used by Chinese EFL learners, to study the patterns of Chinese EFL learners' use of English is significant.

Although the giving and the responding of compliments are regarded as universal speech actions, ways of giving and responding to them are different in different cultures. Spencer (1993, p. 99) pointed out that English Speakers' and Chinese have different concepts of politeness in compliment responses. Responding to a compliment is also a dilemma for speakers (Pomerantz, 1978, pp. 79-112). The reason is that speakers have to consider two conversational principles. Conversation participants have to agree with others' compliment, meanwhile, they have to avoid self-praise. When responding to a compliment, how to balance these two conflicting principles is a problem to Chinese English Learners because in Chinese culture, to avoid self praise is more emphasized. The standard mode of Chinese responses to compliments is rejection or denial.

For example:

A: well done!

B: you've over-praised me. I am not as good as you think. 
Several studies have been done on compliments and compliment responses in great details in twelve different languages and in six varieties of English alone. (Golato, 2005, p. 1) Several comparative studies also have been done between several English varieties and other languages. (Urano, 2000) However, these studies do not consider of language learners' behaviors when they speak the target language. Furthermore, there are a few studies on the pragmatic features of Chinese English learners' behavior in responding to a compliment in English. Whether Chinese EFL learners still apply pragmatic principles based on Chinese culture when they respond to compliment in English is unknown. It is worth to study how Chinese English learners respond to compliments in English. Whether Chinese EFL learners respond to compliment in an appropriate way in English could be detected. The results of this study might help Chinese English teachers to help Chinese English learners to respond to compliments in English in a more appropriate way.

Therefore, the main purpose of this study is to examine how the Chinese college students respond to compliments in English. The specific research questions are raised as follows:

1) What are the patterns of Chinese EFL learners' responses to compliments in English?

2) What are the pragmatic features of Chinese college EFL learners' responses to compliments in English?

3) Do the gender and the status of the producer of compliments, the formality of the situation, and the type of the compliments could influence Chinese English learners' responses to compliments in English?

\section{Theoretical Background}

As a speech event that has been studied as a major area, the compliments and compliment responses were studied as phenomenon of the politeness in the last decades. Manes (1983), Wolfson and Manes (1981), Herbert (1990) studied the compliment behaviors in American English. Holmes (1986) studied the compliment behaviors in New Zealand English. All of these researches on compliment speech act made several contributions.

\subsection{Previous Studies on Compliments and Compliment Responses}

The compliment speech event is a serial of utterances that has the structure of an adjacency pair operation (Schegloff \& Sacks, 1973, p. 296). The compliment speech event consists of two parts: compliments and compliment responses. As the topic of this research, it is necessary to explain the definitions of compliments and compliments responses.

As a positive politeness strategy, the concept of compliment was defined by Holmes as follows:

'A compliment is a speech act which explicitly or implicitly attributes credit to someone other than the speaker, usually the person addressed, for some 'good' (possession, characteristic, skill, etc.) which is positively valued by the speaker and the hearer.' (Holmes, 1986, p. 485) From this definition, it is clear to see that the compliment is the act of attributing positive comments by the utterance producer to the recipient.

There are two types of compliment speech act. (Herbert, 1989) According to their linguistic forms, compliments could be either explicit (e.g., your skirt is beautiful. I like it) or implicit (e.g., I wish I could finish this work like you did). Explicit compliments can be easily recognized as compliments. Herbert (1989) divided the explicit compliment into four types: A. the adjectival explicit compliments, B. the adverbial explicit compliments, C. the verbal explicit compliments and D. the nominal explicit compliments. Examples are as follows: A. your dress is very beautiful. B. You perform pretty well. C. This handbag suits you. D. She has beautiful hands. Actually, the classification of explicit compliments is a development of the formula of compliments.

The implicit way is a little bit hard to be recognized because the compliments are hiding in the literal meaning. In explicit compliments, the utterances that attribute compliment are very clear to others because the good point is positively valued by the speaker. Implicit compliments are a kind of compliment that could not be recognized directly because the compliments on the recipient are not directly related to the recipient in the utterance. That is to say, the compliments do not clearly relate to the things done by the receiver or the characteristics of the receiver in the utterance (Holmes, 1988). For example

context: Robert drew a painting.

Robert's mother: wow, this painting is wonderful. I should find a good teacher for you.

Robert: Thanks mom.

Relatively, a compliment response 'is a verbal acknowledgement that the respondent of the compliment heard and reacted to the compliment' (Nelson et al., 1996, p. 413). In other words, the compliment responses depend on the existence of compliments. Thus, responses to explicit and implicit compliment could be different. Therefore, whether Chinese English learners could realize the English implicit compliment and response to it as 
they respond to explicit compliment is worth to investigate.

\subsection{Studies on Compliment Response}

Pomerantz (1978, pp. 79-112) pointed out that in every compliment speech act, the recipients of a compliment were always in a dilemma that they had to agree with the complimenter and accept the complement while they also have to avoid self-praise. Therefore, responses could reflect the recipient's decision. She also pointed out that there was a wide range of compliment responses types. Pomerantz's analysis of the data, which were collected in America, also showed that although the appreciation token and acceptance were accepted as normal models of responses to compliments, people did other responses when they were complimented.

Based on Pomerantz's research, Herbert (1986:78) distinguished there were twelve types of compliments responses. Herbert also gave the definitions and explanations of each type. They are simplified as follows:

1) Appreciation Token, in which the receipt of the compliment accepts the compliment verbally or nonverbally.

2) Comment Acceptance in which the receipt of the compliment accepts the compliment by a relevant comment on the compliment topic personally.

3) Praise Upgrade, in which the receipt of the compliment accepts the compliment and claims the insufficient of the compliment.

4) Comment History, in which the receipt of the compliment comment on the object complimented impersonally.

5) Reassignment, in which the speaker accepts the compliment by transferring to something else rather than himself.

6) Return, in which the speaker accepts the compliment by returned to the first speaker.

7) Scale Down, in which the receipt disagrees with the compliment.

8) Question, in which the receipt questions the compliment itself.

9) Disagreement, in which the receipt denies the compliment.

10) Qualification, in which the receipt re-qualifies the objects complimented.

11) No Acknowledgement, in which the receipt did not respond to the compliment.

12) Request Interpretation, in which the receipt considers the compliment as a request. This is a misunderstanding of the compliment.

Then, Herbert categorized these twelve types compliment responses into three categories: Agreement, Non-agreement, and Other Interpretations. Thereafter, in a contrastive study on American and South African compliment responses (1989), Herbert improved the categorization and listed examples of responses with the compliment part. In order to show these types of compliment responses clearly, these two categorizations are combined and listed as follows. 
Table 1. Compliment responses types (Herbert, 1986, p. 79; 1989, p. 39)

\begin{tabular}{|c|c|c|c|}
\hline Response Type & & & Example \\
\hline \multirow[t]{6}{*}{ A. Agreement } & \multirow[t]{3}{*}{ I. Acceptances } & 1.Appreciation Token & $\begin{array}{l}\text { A: Your handwriting is good. } \\
\text { B: Thanks; thank you; [smile] }\end{array}$ \\
\hline & & 2.Comment Acceptance & $\begin{array}{l}\text { A: I like your sunglasses. } \\
\text { B: Thanks; it's my favorite too. }\end{array}$ \\
\hline & & 3. Praise Upgrade & $\begin{array}{l}\text { A: Your eye shadow is fashionable. } \\
\text { B: Really brings out the blue in my eye, doesn't it? }\end{array}$ \\
\hline & \multicolumn{2}{|c|}{ II. Comment History } & A: Your necklace is very beautiful. \\
\hline & \multirow[t]{2}{*}{ III. Transfers } & 1. Reassignment & $\begin{array}{l}\text { B: I bought it for the trip to Arizona. } \\
\text { A: I like your shoes. } \\
\text { B: My brother gave it to me. }\end{array}$ \\
\hline & & 2. Return & $\begin{array}{l}\text { A: Your eyes are so beautiful. } \\
\text { B: So's yours. }\end{array}$ \\
\hline \multirow[t]{5}{*}{ B. Non-agreement } & \multicolumn{2}{|l|}{ I. Scale Down } & $\begin{array}{l}\text { A: Your scarf is fashionable. } \\
\text { B: It's really quite old. }\end{array}$ \\
\hline & \multicolumn{2}{|l|}{ II. Question } & $\begin{array}{l}\text { A: You look great. } \\
\text { B: Do you really think so? }\end{array}$ \\
\hline & \multirow[t]{2}{*}{ Non-acceptances } & 1.Disagreement & $\begin{array}{l}\text { A: I like your house. } \\
\text { B: I hate it. }\end{array}$ \\
\hline & & 2. Qualification & $\begin{array}{l}\text { A: Your handbag is cool. } \\
\text { B: It's all right, but Len's is nicer. }\end{array}$ \\
\hline & \multicolumn{2}{|c|}{ IV. No Acknowledgement } & $\begin{array}{l}\text { A: You are so smart. } \\
\text { B: [silence] }\end{array}$ \\
\hline C. Other Interpretations & \multicolumn{2}{|l|}{ I. Request } & $\begin{array}{l}\text { A: Wow, I really like your CD player. } \\
\text { B: You wanna borrow this one too? }\end{array}$ \\
\hline
\end{tabular}

Therefore, it is obvious that in conversation, there are several ways of responding to compliments.

Based on fundamental studies above, differences of CR between different languages and culture were studied in a large amount of comparative investigation. (Holmes, 1988; Herbert \& Straight, 1989; Chen, 1993) In Holmes's research on New Zealand English, he found out that people in New Zealand preferred to accept compliment more than people in Malay. In Herbert's research on Americans and South Africans, the result shows that in South African English CR, acceptance was applied twice as much as in American English. In Chen's research in 1993, the difference between America English and Chinese was discussed. Based on DCT, all most all of Chinese reject in CR and only five percent subjects accept the compliment.

Therefore, to investigate how Chinese English learners respond to compliment in English is meaningful because their preference of $\mathrm{CR}$ is unknown. In this research, the data will be compared to those patterns that Herbert proposed and find out whether Chinese English learners apply these patterns in their responses to a compliment in English. This research will also find out that whether Chinese EFL learners respond to compliment in English in a way that did not list in this table. The specific patterns of Chinese English learners' response to a compliment could be concluded through these findings.

\subsection{Studies on Influences of Gender, Social Status on Compliment Speech Act}

Although there are few researches about the influence of gender variable in compliment speech act, Holmes (1988) and Herbert (1990)'s research investigated this topic in great details. In Holmes's research, based on the complimenting behaviour in New Zealand, differences in the way women and men use compliments and compliment responses are studied. This research has several significant findings such as (Holmes, 1988, p. 463)

(i) women give and receive significantly more compliments than men do

(ii) women more often use syntactic form which could strengthens the positive force of the compliment significantly than man do.

(iii) women compliment each other on appearance more then on any other topics.

These features of the gender differences on compliments were reinvestigated by Herbert in 1990. Herbert did a more detailed investigation on the sex-based compliment responses. In this research, Herbert investigated man's responses to both gender as well as women's in twelve different CR types. The results showed that the differences in response type frequencies between men and women are more impressive than the differences in compliment. For example, female recipients tent to accept compliments from males, whereas compliments from 
females will most likely not be accepted. Furthermore, this great tendency 'is consistent with the notion that acceptances are most common among status non-equal' participants $(1990$, p. 217). Then there is a question, whether gender could influence Chinese EFL learners' responses to compliment in English as what have found in researches above. Therefore, the variable of gender is chosen as one variable of this research.

Holmes (1988), Herbert (1989, 1990)'s researches could reveals influences of social status on compliment responses. In Holmes's research, complimenters tended to focus on recipient's skills or performance when participants of the conversation in different status. Furthermore, Herbert (1989, p. 44) found out that higher placed person tended to be initiating the compliment in conversation between unequal participants. In other words, the status of the participants could influence the producer of compliments. In a further research, Herbert figured out that "the increased frequency of acceptance responses to male compliments by female addresses may be yet another manifestation of the linguistic consequences of status differences apparent in corss-sex interactions" (1990, p. 217). All of the research above revealed that compliments and CR could be influenced by social status and gender of participants. In addition, in Chinese culture, to show great esteem to older generation and superior is regarded as a consensus politeness principle shared by every member of the society. Thus, it seems that social status might also influence Chinese English learners' CR to compliment in English. Therefore, social status of participants is also chosen as one variable of the present research.

To conclusion, in daily communication, there is a big difference between participants of different gender and social status. Thus, in order to investigate Chinese EFL learners' CR, these variables should be considered.

\section{Methodology}

\subsection{Selection of the Data Collection Method}

As Golato (2005: 21) states, there were five methods that have been used to investigate the compliment speech act in previous studies. These methods were DCTs (Discourse completion tasks) and questionnaires, role plays, field observations, recall protocols, recordings of naturally occurring talk in interaction. In the following, the advantages and disadvantages of every data collection method discussed by Golato (2005) will be summarized. Why the role play method is chosen to complete this research will be explained as well.

In DCTs and questionnaires, 'subjects are presented with a situation in which a compliment (or a compliment response) is believed to be the next relevant action. Subjects are then invited to note what they would say or how they would react in this situation.' (Golato, 2005, p. 12) This data collection method is effective and allows research to gather large amounts of data in a short time. This method also could control for the certain variables (such as features of the situation, gender and age of the people who do the compliment.) Although DCTs have a lot of advantages, the data collected through is not completely natural. The reason is that the data just reflect what subjects believe to be the most appropriate responses rather than the real conversation in daily life.

Comparing with DCTs, role play could provide more naturalistic data. Crookall and Saunders defined that 'role play is a social or human activity in which participants take on and act out specified roles, often with in a predefined social framework or situational blueprint.' (1989, pp. 15-16) Role play allows researchers to collect data under control of extra-linguistic variables such as social status, gender and so on (Kasper, 2000). Meanwhile, role play could also collect large amount data in a short time. However Kasper (2000) pointed out that this method could be influenced by the researcher's aims rather than real interaction.

The recall protocols, which means that to make the subject recall the latest speech he did (Golato, 2005, p. 17), is also a possible method for collecting data. However the quality of data collected through this method relies heavily on the memories of subject. Therefore, the data is not reliable since it is subjective. Through the field observation and the recordings of naturally occurring talk, the most natural data could be collected. Although these methods are ideal data collection methods for this research since the most natural data could be collected, the crucial problem is that the data collection period could be very long. Furthermore, these methods cannot control the variables because the compliment behavior in the real life is various. For the more, the data is not representative due to the localization of the observer (Wolfson, 1983).

In this research, a large amount of data, which should be as natural as possible and controlled by variables of gender, the social status of the producer of compliments, the formality of the situation, and the type of the compliments, is needed to be collected. After a careful measure, although there is a possibility of influencing the data, the role play is chosen as the data collection method in the present study because through role play a large amount of relative natural data could be collected in a short time.

\subsection{Data Collection Procedure}

The data of this research were collected by role play. The research is conducted in the following two steps. In the 
role play, subjects in this research play the role of the accepter of the English compliment. Therefore, the addresser of the compliment is needed. In order to make the context more natural, short films were recorded based on the scenes shown on Appendix I.

These scenes are inspired by and designed according to Yu's (1999) discussion. Compliment topics are mainly on accomplishment of duty, personal abilities, skills, appearance. The situations of compliments are chosen in daily life. In order to get data that could be analyzed to answer the research questions, these eight scenes are designed under control. Scene I, III, IV, VII and II, V, VI, VIII are compliments from female and male separately. Scene I, V, VII, VIII are compliments made by people from higher social status while scenes I, III, IV, VI are compliments made by equal social status. Scenes I, III, VI, VIII are in formal situation while scenes II, IV, V, VII are in informal situation. The influence of the type of the compliments could be shown in scenes I, IV, V, VIII. The scenes were categorized as table 2 shown.

Table 2. Variable condition of each scene

\begin{tabular}{|c|c|c|c|c|c|c|}
\hline $\begin{array}{l}\text { Compliment } \\
\text { scenes }\end{array}$ & $\begin{array}{l}\text { Compliment } \\
\text { Topic }\end{array}$ & $\begin{array}{l}\text { Compliment } \\
\text { Situation }\end{array}$ & $\begin{array}{l}\text { Gender of the } \\
\text { Complimenter }\end{array}$ & $\begin{array}{l}\text { Formality of } \\
\text { the Situation }\end{array}$ & $\begin{array}{l}\text { Status of the } \\
\text { Complimenter }\end{array}$ & $\begin{array}{l}\text { Type of the } \\
\text { Compliments }\end{array}$ \\
\hline III. & Accomplishment & Meeting & Female & Formal & Higher Status & Explicit \\
\hline I. A & Ability & Seminar & Female & Formal & Same Status & Explicit \\
\hline I. B & Ability & Seminar & Female & Formal & Same Status & Implicit \\
\hline IV. A & Skill & Encounter & Female & Informal & Higher Status & Explicit \\
\hline IV. B & Skill & Encounter & Female & Informal & Higher Status & Implicit \\
\hline VII. & Appearance & Supermarket & Female & Informal & Same Status & Explicit \\
\hline VI. & Accomplishment & Conference & Male & Formal & Higher Status & Explicit \\
\hline VIII. A & Ability & Seminar & Male & Formal & Same Status & Explicit \\
\hline VIII. B & Ability & Seminar & Male & Formal & Same Status & Implicit \\
\hline II. & Skill & Encounter & Male & Informal & Higher Status & Explicit \\
\hline V. A & Skill & Picnic & Male & Informal & Same Status & Explicit \\
\hline V. B & Skill & Picnic & Male & Informal & Same Status & Implicit \\
\hline
\end{tabular}

Then, these short films were shown to the subjects. Their responds were recorded and collected immediately. In order to make the data authentic, each subject was tested only once. In the directions before the play of the scenes, the situation of the scene was told to subjects. Then the films were played for the subject. The subjects would be asked to respond to the film as soon as possible and their responses were recorded at the same time.

The same as the number of the subjects, the expectant number of the data in the research are 360 . Unfortunately, three records were damaged and one record was lost during the data collection. One record cannot be used as data because the subject totally misunderstanding the test. Therefore, there are 355 available records of the oral responses altogether.

\subsection{Selection of the Subjects}

Chinese college EFL learners are chosen to be the subjects because undergraduate students are gained a comparatively higher level in English studying. All together, 360 students participated in this research. The gender proportion is fifty-fifty. These students are 2nd grade undergraduate students aged 19 to 20 from eight different universities in Xi'an. They come from almost every province in China. They speak Chinese as their first language and have learned English more than six years. All of the subjects are not English major. Their fields and majors of study are various. The selection of the subjects reduced the influence of the localization of the subjects into the lowest level and makes the data as representative as possible. Subjects in this study are divided into 8 groups. There are 30 students in each group of II, III, VI, and VII. Group I, VI, V and VIII consist of 60 students in each one. The information of subjects is shown in table 3.

Table 3. Information of subjects—-total number: 360

\begin{tabular}{lllllllllllll}
\hline Group & $1 \mathrm{~A}$ & $1 \mathrm{~B}$ & 2 & 3 & $4 \mathrm{~A}$ & $4 \mathrm{~B}$ & $5 \mathrm{~A}$ & $5 \mathrm{~B}$ & 6 & 7 & $8 \mathrm{~A}$ & $8 \mathrm{~B}$ \\
\hline Number of Males & 15 & 15 & 15 & 15 & 15 & 15 & 15 & 15 & 15 & 15 & 15 & 15 \\
Number of Females & 15 & 15 & 15 & 15 & 15 & 15 & 15 & 15 & 15 & 15 & 15 & 15 \\
\hline
\end{tabular}




\subsection{Data Analysis Method}

When all of the data were recorded, the responses of the subjects to the given compliments were transcript. Then these transcriptions were categorized and the percentage of the frequency will be counted with the reference of Herbert's research on the type of the compliment responses (1986).

The final step is to analyze the data. The gender difference of Chinese English learners' CR in English could be analyzed by comparing data groups I, III, IV, VII and II, V, VI, VIII. The influence of the status of the producer of compliments could be analyzed by comparing data groups I, V, VII, VIII and II, III, IV, VI. The influence of the formality of the situation could be analyzed by comparing data groups I, III, VI, VIII and II, IV, V, VII. The influence of the type of the compliments could be analyzed by comparing the explicit data groups within implicit ones. In addition, some other features of Chinese EFL learners' compliment might be revealed and therefore will be analyzed.

\section{Data Analysis and Discussion}

According to Herbert's (1986) studies, people always respond to compliments in twelve different possible ways, they are appreciation token, comment acceptance, praise upgrade, comment history, reassignment, return, scale down, question, disagreement, qualification, no acknowledgement and other interpretations such as request. Herbert also categorized these CR types into three categorizations: agreement, non agreement, and other interpretations. This categorization of types of compliment responses of Herbert is the most appropriate framework for analyzing the data collected in the present study. However, through the analysis of subjects' records, it is found that although Herbert listed all types of CR, in this research some of the subjects responded to compliment in English in some ways that did not list in this categorization. For example: subjects could expect progresses of themselves or their team in the future.

e.g., Scene III

11. A: This is good! This essay is excellent.

S: Oh thank you. I can do it better.

Subjects could also attribute their success to teamwork, fortune or the work of complimenter.

e.g., Scene IB

20. A: I wish I could thought of that.

S: Oh I I think you also have a good idea. Um I think (.) I'm just lucky.

In addition, subjects could respond to compliment responses which listed in Herbert's system in several different ways. For example, subjects could apply the appreciation token in two ways: A. Thank you or B. I'm glad to hear that. / It's my pleasure to hear that. Therefore, subjects' records were concluded and all of the CRs that did not list in Herbert's classification were hunted out. Then Herbert's categorization was reorganized and subjects' records were statistically analyzed according to the improved framework one group by one group. The re-categorization is showed in table 4. 
Table 4. General features of Chinese College English Learner's CR

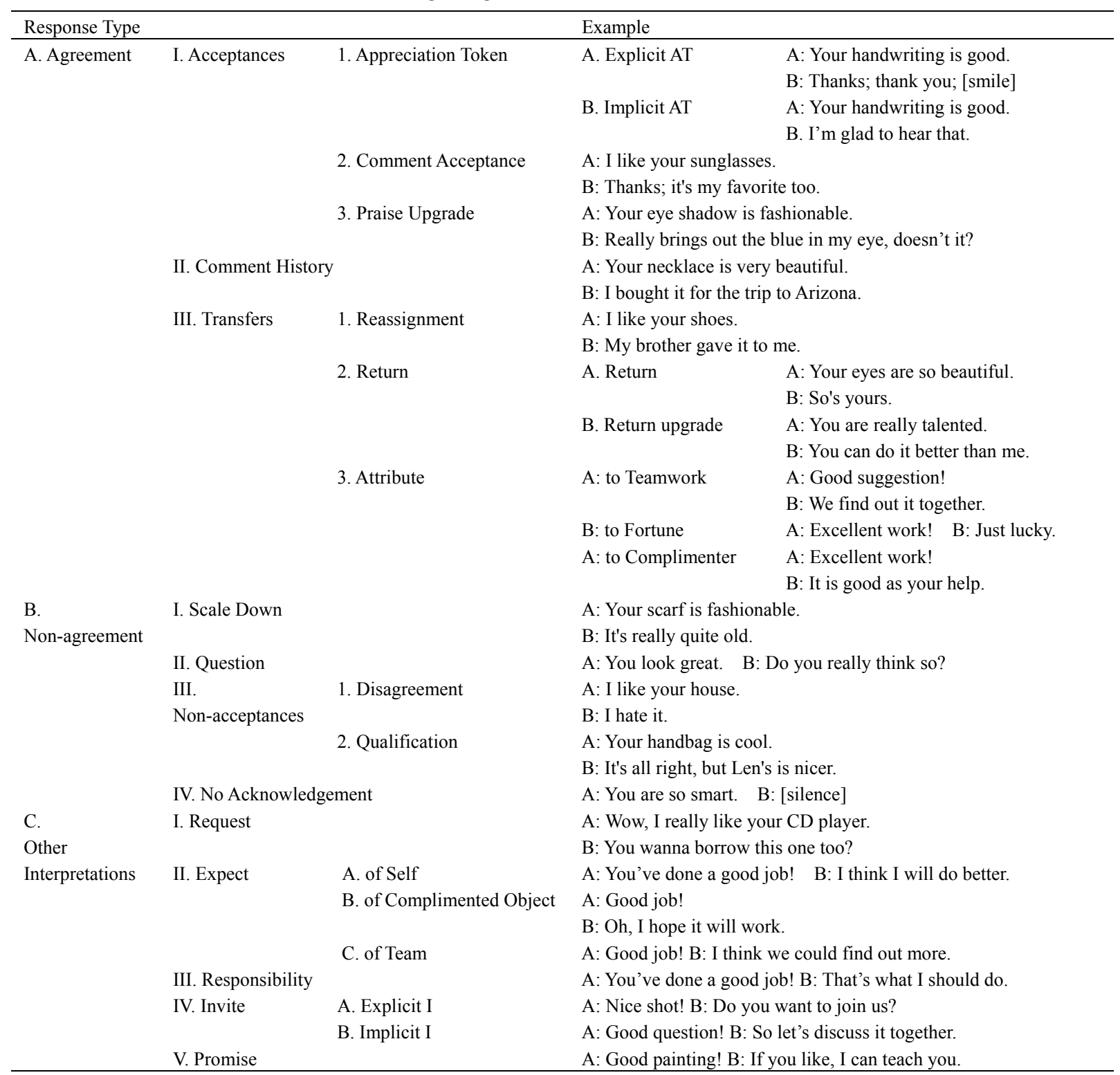

\subsection{General Overview of the Compliment Response Strategies Employed by Chinese EFL Learners}

The most obvious feature is that all most ninety percent (89.86\%) of subjects accept the compliments in English. Among the acceptance strategies, more than three quarters of the subjects $(85.63 \%)$ applied appreciation token as their CR strategies. The data also reflects that when subjects apply the appreciation token as the CR strategy, they do it in two different ways: explicit appreciation token and implicit appreciation. The direct way is most popular. (66.48\%) Meanwhile, only $4.79 \%$ of the subjects took the compliments indirectly.

However, $14.37 \%$ of the subjects respond to the compliments both directly and indirectly. For example:

Scene II

A: Nice shot!

7. S: Ok thank you. It's very kind of you to say so.

8. S: Thank you so mu:ch. hh. It's very good to hear that.

However, only $3.38 \%$ of the subjects accept the complimentary force with a relevant comment on the appreciated topic'. In the aspect of praise upgrade, only four subjects apply this type of acceptance $(1.13 \%)$. 
Table 5. Frequency of acceptances

\begin{tabular}{|c|c|c|c|c|c|}
\hline \multicolumn{2}{|l|}{ Type of CR } & \multicolumn{4}{|c|}{ Total } \\
\hline & & \multicolumn{2}{|c|}{ Number } & \multicolumn{2}{|c|}{ Percentage } \\
\hline I. Acceptances & Appreciation Token & 304 & A. 236 & $85.63 \%$ & $66.48 \%$ \\
\hline \multirow[t]{4}{*}{$89.86 \%$} & & & B. 17 & & $4.79 \%$ \\
\hline & & & A/B. 51 & & $14.37 \%$ \\
\hline & Comment Acceptance & 12 & & $3.38 \%$ & \\
\hline & Praise Upgrade & 4 & & $1.13 \%$ & \\
\hline
\end{tabular}

In the opinion of Honna (2006, p. 117), Chinese EFL students speak English based on Chinese pragmatics. "I'm not that good. You've over praised me' is the response to a compliment heard more frequently than 'thank you". However, based on the data of this research, although there are still a few subjects respond to compliment in a normal Chinese pattern (scale down and disagreement, 8.17\% altogether), great majority subjects do accept the compliment first. This partly reflects that a majority of Chinese English learners do not reject compliments as they did in Chinese language any more. In addition, the infrequency use of praise upgrade shows that Chinese English learners obey the first rule of modesty maxim of Leech's politeness principle. They do minimize praise of themselves through avoiding praise upgrade.

All in all, majority of Chinese English learners accept compliments in English currently. This tendency shows that they know to maintain complimenters' faces through acceptance is the most appropriate way to respond to compliments in English. They know to minimize disagreement and maximize agreement between self and other is the standard politeness principle when they use English. Furthermore, they apply implicit appreciation token and avoid praise upgrade in order to minimize praise of self. In this way, they maintain complimenters' faces.

\subsection{Mixed Usage of Compliment Response Strategies}

A general overview of CR strategies that Chinese EFL learners could apply is shown in the above. This overview indicates that Chinese EFL learners could apply various CR strategies to show polite. However, the data reveals that the subjects did not respond to the compliment with only one strategy. They applied two, three or even more strategies in responses. Since the reason and the influence of this CR pattern are unknown, it is necessary to analyze this phenomenon in detail.

According to the data, there are three patterns of Chinese English learners' CR generally. They are as follows: A). Appreciation Token + Expect B). Appreciation Token + Scale Down and C). Appreciation Token + Return.

\subsubsection{Appreciation Token + Expect}

Altogether, $15.77 \%$ percent of the subjects (56 out of 355) applied this CR pattern. Comparing with the frequency of the expect strategy $(17.46 \%)$, it is clear that most subjects showed their expectation of themselves, their groups or the complimented objects after the acceptance to the compliments. A typical example of this patter is shown as follow.

e.g., Scene II

\section{A: Nice shot!}

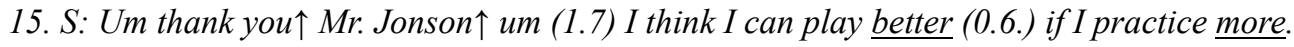

This phenomenon reflects that Chinese English learners tend to mixed apply Leech's politeness principle. They tend to maximize agreement between self and other, and at the same time they minimize the praise of themselves without hurting complimenters' faces when they are complimented in English.

\subsubsection{Appreciation Token + Scale Down}

A typical example of this patter is as follow.

\section{e.g., Scene III A}

\section{A: This is good. This essay is excellent.}

\section{S: Thank you. (2.8) But I think. hh <it's:: um not very best.>}

18 subjects accepted compliments with a disagreement with the complimentary force. It seems that this patter is seldom applied by Chinese English learners (5.07\%). Comparing with the number of the subjects who claimed the overstated of the compliments $(7.04 \%)$, it is obvious that although some subjects still responded to compliments in English accommodating Chinese based pragmatics, nearly three quarter of these subjects tried to avoid hurting complimenters' faces by appreciating the complimenter. In brief, some Chinese English learners 
could combine the Chinese pragmatics and English pragmatics together in one utterance in CR.

Therefore, although a large majority of Chinese English learners do say 'thank you' to complimenter, it seems that this appreciation token does not mean that the recipient has completely accepted the compliment completely. They actually accept the compliment to a certain extent. In other words, to say 'Thank you' just means 'I appreciate you compliment me' much more than agreement with the compliment for Chinese English learners.

\subsubsection{Appreciation Token + Return}

This is an example of this CR pattern:

e.g., $I V B$

\section{A: Wow, I wish I could paint like that!}

18. S: Um. Thank you. If you try you can do it.

58 subjects (16.34\%) employed this CR pattern. It should be pointed that since most of the return strategies are applied in certain condition and so closely related to scenes, to compare this proportion with the frequency of the return strategy is erroneous. However, this proportion still could reflects that a number of Chinese English learners attempt to return the compliment back to the complimenter. Through this patter, they maximize the praise of other after the appreciation.

In conclusion, Chinese English learners tend to apply the appreciation token strategy with expect, scale down and return strategies. This mixed usage of the compliment reflects that Chinese EFL learners accommodate mixed pragmatic principles of Chinese and English pragmatics. This phenomenon reveals that although Chinese EFL learners used some of the strategies which could threaten the complimenter's face, they try their best to be polite. In addition, 'thank you' means appreciation more than agreement to Chinese English learners.

\subsection{Gender Differences in CR (Note 1)}

Holmes (1988) and Herbert's (1990) researches find out that there are gender differences in compliment speech acts. However, whether the gender could influence the CR of Chinese English learners is unknown. Therefore, gender is chosen as a variable that should be studied in the present research. Before the investigation, it was realized that the best way to research gender-based differences in compliment responses was to research subjects' responses to the exact same compliment from male and female in English under similar or totally the same circumstance. However, the authenticity is more important in this research. Subjects could be aware of the aim of the research if they were tested twice or more. Therefore, gender differences were just studied generally.

In order to investigate gender difference, 180 female and 180 male students participated in this study. In each scene, the number of female and male is equal. This distribution aims to avoid the influence of the scenes. When the transcription was finished, these records were divided into four categories: female responses to female, female responses to male, male responses to female, male responses to male. Finally, every CR strategies that subjects applied were compared statistically. Through analysis, it is found out that both complimenters' gender and recipient's gender could influence Chinese English learners' responses to compliments in English; therefore, I discuss the influence of gender in these two categories.

\subsubsection{Influence of Complimenters' Gender}

With the regard to appreciation token response, it seems that female subjects preferred to accept the praise from male directly (32.40\%) while only $28.49 \%$ female accepted the praise from female directly. On the contrary, female subjects tended to accept compliments from female indirectly (3.91\%: $2.23 \%)$. For male subjects, they preferred to accept compliments from male directly (35.96\%:32.22\%). They preferred to accept praises from female indirectly. The generalization is that praises from male are accepted directly. In addition, both gender tended to accept praises from female indirectly. Therefore, the sex of the complimenter could influence Chinese EFL learners' CRs. 
Table 6A. Detailed statistics of CR to female and male (female responses)

\begin{tabular}{|c|c|c|c|c|c|c|c|c|}
\hline \multirow{3}{*}{$\begin{array}{l}\text { Type of CR } \\
\text { Appreciation Token }(84.92 \%)\end{array}$} & \multicolumn{4}{|c|}{ Group 1, 3, 4, 7 Female to Female } & \multicolumn{4}{|c|}{ Group 2, 5, 6, 8 Female to Male } \\
\hline & \multicolumn{2}{|c|}{ Number } & \multicolumn{2}{|c|}{ Percentage } & \multicolumn{2}{|c|}{ Number } & \multicolumn{2}{|c|}{ Percentage } \\
\hline & 75 & A. 51 & $41.90 \%$ & $28.49 \%$ & 77 & A. 58 & $43.02 \%$ & $32.40 \%$ \\
\hline & & B. 7 & & $3.91 \%$ & & B. 4 & & $2.23 \%$ \\
\hline & & A/B.12 & & $6.70 \%$ & & A/B. 15 & & $8.38 \%$ \\
\hline \multirow[t]{3}{*}{ Return $(25.69 \%)$} & 27 & A. 18 & $15.08 \%$ & $10.06 \%$ & 19 & A. 10 & $10.61 \%$ & $5.59 \%$ \\
\hline & & B. 8 & & $4.50 \%$ & & B. 9 & & $5.03 \%$ \\
\hline & & A/B.1 & & $0.56 \%$ & & A/B.0 & & $0 \%$ \\
\hline \multirow[t]{2}{*}{ Expect $(21.23 \%)$} & 22 & A. 13 & $12.29 \%$ & $7.26 \%$ & 16 & A. 13 & $8.94 \%$ & $7.26 \%$ \\
\hline & & B. 9 & & $5.03 \%$ & & B. 3 & & $1.68 \%$ \\
\hline
\end{tabular}

Table 6B. Detailed statistics of CR to female and male (male response)

\begin{tabular}{|c|c|c|c|c|c|c|c|c|}
\hline \multirow{3}{*}{$\begin{array}{l}\text { Type of CR } \\
\text { Appreciation Token }(85.45 \%)\end{array}$} & \multicolumn{4}{|c|}{ Group 1, 3, 4, 7 Male to Female } & \multicolumn{4}{|c|}{ Group $2,5,6,8$ Male to Male } \\
\hline & \multicolumn{2}{|c|}{ Number } & \multicolumn{2}{|c|}{ Percentage } & \multicolumn{2}{|c|}{ Number } & \multicolumn{2}{|c|}{ Percentage } \\
\hline & 80 & A. 58 & $44.44 \%$ & $32.22 \%$ & 73 & A. 64 & $41.01 \%$ & $35.96 \%$ \\
\hline & & B. 6 & & $3.33 \%$ & & B. 1 & & $0.56 \%$ \\
\hline & & A/B.16 & & $8.89 \%$ & & A/B. 8 & & $4.49 \%$ \\
\hline \multirow[t]{2}{*}{ Return (22.33\%) } & 22 & A. 20 & $12.22 \%$ & $11.11 \%$ & 18 & A. 15 & $10.11 \%$ & $8.43 \%$ \\
\hline & & B. 2 & & $1.11 \%$ & & B. 3 & & $1.68 \%$ \\
\hline \multirow[t]{2}{*}{ Expect (13.97\%) } & 12 & A. 11 & $6.67 \%$ & $6.11 \%$ & 13 & A. 12 & $7.30 \%$ & $6.74 \%$ \\
\hline & & B. 1 & & $0.56 \%$ & & B. 1 & & $0.56 \%$ \\
\hline
\end{tabular}

The return strategy applied more often by female $(25.69 \%)$ than male $(22.33 \%)$. This phenomenon reflects that female is in preference to establishing coordination between complimenters and recipients. In detail, complimenters' gender influenced subjects' selection of the return strategy. Compliments from females are more likely to be returned back to complimenters compared with praised from males. Both of the female and male return strategies are more likely to be expressed simply to complimenters more than to be expressed by means of upgrade the return praise.

\subsubsection{Influence of Recipients' Gender}

With the regard to appreciation token response, the data clearly shows that generally speaking most subjects of both gender accepted the compliments $(84.92 \%, 85.45 \%)$. The difference is that female subjects tended to accept compliments from male $(43.02 \%)$ rather than female $(41.90 \%)$. On the contrary, male subjects tended to accept compliments from female (44.44\%) rather than male (41.01\%). This result is consistent with Herbert's previous studies (1990). Herbert found out that female recipients tended to accept compliments from males, whereas compliments from females will most likely not be accepted. Data of this research also shows that for Chinese English learners, male recipients tend to accept compliments from females rather than males.

On the aspect of comment acceptance, praise upgrade and comment history strategies, the frequency of each strategy applied by female and male to compliments from both gender is similar. However, when male subjects responded to compliments from female, it seems that they seldom accepted with a comment on the complemented objects impersonally or subjectively.

In the aspect of scale down strategy, the gender distribution is average, except that female responses to female compliments happened more often than other categories. This could be ample evidence besides the using of the return strategy that female prefer to establishing coordination between complimenters and recipients. The difference is that female achieves this goal positively by applying the return strategy. Oppositely, although the original intention is not to offend complimenter, female attempt to show polite negatively by applying scale down strategy.

Since there is no big gender difference on the frequency of the question, disagreement, qualification strategies, and the request interpretation is not applied by any subject, these strategies will not be discussed. In the aspect of no acknowledgement, only $0.56 \%$ of the subjects did not respond to the compliment, both of them are male, this revealed that male subjects are not susceptible or they do not express their emotion vividly like women. Inspired by this, the transcription was reexamined and it is found out that male subjects always responded to compliments with few words and few CR strategies. Oppositely, female tended to responded to compliments with more words and apply more CR strategies. 
The difference on the frequency of the expect strategy clearly shows that female subjects $(21.23 \%)$ preferred to express their expectations for the future compared with male subjects $(13.97 \%)$. The frequency of the responsibility strategy shows that male subjects tended to minimize praise of self by applying this strategy when they are complimented.

In conclusion, the gender of the compliment and the recipient could influence Chinese English learners' CR strategies. Chinese EFL learners tend to accept compliments from the opposite sex more than from the same sex. Both genders tend to accept praises from male directly and from female indirectly. Male Chinese EFL learners tend to respond to compliments with few words and CR strategies, while female learners are totally different. After all, the gender difference is a significant restraint element of Chinese EFL learners in compliment speech acts in English

\section{Conclusion}

This research was undertaken to study the pragmatic features of Chinese EFL learners' compliment responses. According to this research, majority of Chinese English learners accept the praise when they are complimented in English. Seldom Chinese English learners still apply non agreement as CR strategy as what they did in Chinese.

Chinese EFL learners tend to apply a mixed CR when they are complimented in English, such as A). Appreciation Token + Expect B). Appreciation Token + Scale Down and C). Appreciation Token + Return. Chinese EFL learners prefer to accommodate a combination of pragmatics which is based on Chinese pragmatics and English pragmatics. Propose of this usage might be to obey every maxim in Leech's politeness principle and do not do face threaten acts.

Besides the answer to the research question, there are other significant findings. Although the majority of Chinese college English learners tend to accept compliments in English, this acceptance means appreciation more than agreement. This research also reproved the advantages of Leech's politeness principle. Through discussion, it is found out that Leech's politeness principle met various special politeness principles that based on Chinese culture and Western culture and different pragmatics. This politeness principle could explain the politeness speech act in Chinese culture. In the aspect of research method, as Kasper (2000) have mentioned, this research reproved that the role play could influence the research because role play method could influence the data by the researcher's aims rather than real interaction.

\section{References}

Bolton, K. (2002). Chinese Englishes: from Canton jargon to global English. World Englishes, 21(2), 181-199. http://dx.doi.org/10.1111/1467-971X.00241

Chen, R. (1993). Responding to compliments: A contrastive study of politeness strategies between American

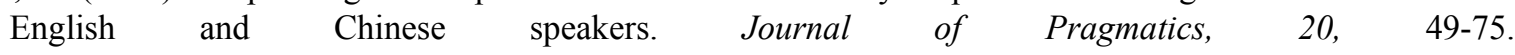
http://dx.doi.org/10.1016/0378-2166(93)90106-Y

Crookall, D., \& Saunders, D. (1989). Communication and Simulation. Clevedon: Multilingual Matters.

Golato, A. (2005). Compliments and compliment responses: Grammatical structure and sequential organization. Amsterdam/Philadelphia: John Benjamin's Publishing Company. http://dx.doi.org/10.1075/sidag.15

Herbert, R. (1986). 'Say ”Thank you”-or something'. American Speech, 61, 76-88. http://dx.doi.org/10.2307/454710

Herbert, R. (1989). The ethnography of English compliment and compliment responses: A contrastive sketch. In W. Olesky (Ed.), Contrastive pragmatics (pp. 3-35). Amsterdam: John Benjamins.

Herbert, R., \& Straight, H. S. (1989). Compliment-rejection VS. compliment avoidance. Language and Communication, 9, 35-47. http://dx.doi.org/10.1016/0271-5309(89)90005-0

Herbert. R. (1990). Sex-based differences in compliment behavior. Language in Society, 19, 201-224. http://dx.doi.org/10.1017/S0047404500014378

Holmes, J. (1986). Compliments and compliment responses in New Zealand English. Anthropological Linguistics, 28(4), 485-508.

Holmes, J. (1988). Paying compliments: a sex-preferential politeness strategy. Journal of Pragmatics, 12, 445-465. http://dx.doi.org/10.1016/0378-2166(88)90005-7

Honna, N. (2006). East Asian English. In B. B. Kachru, Y. Kachru, \& C. L. Nelson (Eds.), The Handbook of World Englishes. Malden, MA: Blackwell. http://dx.doi.org/10.1002/9780470757598.ch7 
Kasper, G. (2000). Four perspectives on L2 pragmatic development. Plenary address, Annual Meeting of the American Association of Applied Linguistics. University of Hawaii.

Manes, J. (1983). Compliments: a mirror of cultural values. In N. Wolfson \& J. Manes (Eds.), Sociolinguistics and language Acquisition (pp. 96-102). Sociolinguistics and language Acquisition.

Manes, J., \& Wolfson, N. (1981). the compliment formula. In Conversational Routine: explorations in standardized situations and pre-patterned speech (pp. 201-231).

Nelson G., \& Echols, E. (1996). Arabic and English compliment responses: Potential for pragmatic failure. Applied Linguistics, 17, 411-432. http://dx.doi.org/10.1093/applin/17.4.411

Pomerantz, A. (1978). Compliment responses: note on the co-operation of multiple constraints. In J. Schenkein (Ed.), Studies in the organization of conversational interaction (pp. 79-112). New York: Academic. http://dx.doi.org/10.1016/b978-0-12-623550-0.50010-0

Schegloff, A., \& Sacks, H. (1973). Opening up closings. Semiotica (pp. 289-327). http://dx.doi.org/10.1515/semi.1973.8.4.289

Urano, K. (2000). Negative pragmatic transfer in compliment responses by Japanese learners of English: A research proposal. University research on Communication and Language Education, 2, 27-38.

Wolfson, N. (1983). An empirically based analysis of complimenting in American English. In Sociolinguistics and language acquisition (pp. 82-95). Rowley: Newbury House Publishers Inc.

Yu, M.-C. (1999). Cross-cultural and inter-language pragmatics: developing communicative competence in a second language. Unpublished doctoral dissertation, Harvard University, Cambridge.

\section{Note}

Note 1. Although Chinese EFL learners are rarely mentioned in the following discussion, all of the discussion is based on the data and thus focuses on the gender differences of Chinese EFL learners' CR strategies.

\section{Appendix A}

Scene I

You are discussing the project you are going to do with your classmates. You give them lots of good advice.

One of your group remarks:

A: Explicit: "Your suggestions are really good. I am sure they'll help us a lot."

B: Implicit: "I wish I'd thought of that!"

Scene II

You are playing tennis with your friends. Dr. Jonson appears and sees you make a great shot.

Dr. Jonson says: "Nice shot!"

Scene III

You are talking to your supervisor Dr. Taylor about your essay.

Dr. Taylor says: "This is good! This essay is excellent."

Scene IV

You are painting in the park. Your professor, Dr. Taylor, appears and notices your work.

Dr. Taylor says:

A: Explicit: "Hey, nice work! You're really talented."

B: Implicit: "Wow, I wish I could paint like that!"

Scene V

You are playing guitar for your friends in a picnic. You play well.

Male friend says:

A: Explicit: "You're really talented!" 
B: Implicit: "Wow, I wish I could play like that."

Scene VI

You are an employee in a company. You have just made a really successful presentation to your clients.

After the meeting, your employer Thomas says: "Well done! You've done a really good job."

Scene VII

You are in a supermarket and come across your good friend Nancy.

Nancy says: "Hi! How are you? You look nice today!"

Scene VIII

You are having a discussion with classmates in a seminar. You raise a very interesting question.

Your male classmate says:

A: Explicit: "Wow, that's a good question!"

B: Implicit: "I wish I'd thought of that!"

\section{Copyrights}

Copyright for this article is retained by the author(s), with first publication rights granted to the journal.

This is an open-access article distributed under the terms and conditions of the Creative Commons Attribution license (http://creativecommons.org/licenses/by/3.0/). 